\title{
Transforming the Old into a Foundation for the New: Lessons of the Moldova ARIA Project
}

\author{
David Ellerman and Vladimir Kreacic \\ World Bank ${ }^{*}$
}

\section{Table of Contents}

Introduction

Two Strategies for Renewal: Replacement or Transformation

The ARIA Project in Moldova

Achieving self-sustainability: long duration of intervention

Achieving self-sustainability: large scale of intervention

Project "Initiation": Find the "Moving Trains"

Finding Leadership

Building Mutual Trust and Understanding

Horizontal Learning by ARIA

Building Local Consulting Capacity

The "PIU Syndrome"

The Foreign Advisor Syndrome

ARIA's Bankruptcy Role

Special Bankruptcy Agency?

No Financing Capacity

Cram-Down Authority

ARIA Restructuring Bankruptcy Program

Choosing the Entry Point: The "Best of the Worst" Principle

SME Spin-Offs

"Industrial Parks" for New Start-ups

Horizontal Learning for Enterprises

Trade Before Investment

"Marshall Plan" Study Tours for Managers

"Marshall Plan" Study Tours for Skilled Blue-Collar Workers

Continuous Improvement Programs

A Hirschmanian Approach to Social Learning and Change

Conclusions

\section{References}

World Bank Policy Research Working Paper 2866, July 2002

The Policy Research Working Paper Series disseminates the findings of work in progress to encourage the exchange of ideas about development issues. An objective of the series is to get the findings out quickly, even if the presentations are less than fully polished. The papers carry the names of the authors and should be cited accordingly. The findings, interpretations, and conclusions expressed in this paper are entirely those of the authors. They do not necessarily represent the view of the World Bank, its Executive Directors, or the countries they represent. Policy Research Working Papers are available online at http:/lecon.worldbank.org.

\footnotetext{
* Vladimir Kreacic was project manager for the project analyzed here, PSD I/II in Moldova.
} 


\begin{abstract}
This paper is a joint DEC-ECA case study of what is recognized as one of the more successful projects in any country of the ECA region, not to mention in the poorest country of the region. The ARIA project showed new ways to attack some of the most intractable problems of private sector development in ECA: how to facilitate reorganization as well as liquidation bankruptcies, how to promote SME spin-offs as well as new start-ups, and how to promote new learning at the enterprise level both in the form of "Marshall Plan" programs with more advanced post-socialist countries as well as continuous improvement programs (e.g., adapted from Japanese programs). The "prime mover" for these programs was the quasi-public restructuring agency ARIA established as part of the Moldova PSD I loan. ARIA was structured in a way to try to combine private sector entrepreneurship with a public function in the process of restructuring and bankruptcy. The case study tries throughout to account for the specific strategies and innovations that lead to the results. Finally the case study tries to connect the ARIA strategy to the older development literature by viewing the case through the lens of Albert Hirschman's work on social learning and change.
\end{abstract}




\section{Introduction}

After a decade of World Bank projects in the transitional economies of Europe and Central Asia, the PSD I/II project in Moldova is recognized as more successful than projects with similar aims in other countries. The areas where the project was relatively successful include:

- $\quad$ Setting up a restructuring agency ("ARIA"),

- Implementing a restructuring bankruptcy ("Chapter 11") program,

- Implementing a liquidation bankruptcy program to seed new start-ups,

- Building up capacity in the local private consulting sector,

- Fostering spin-offs as systematic restructuring strategy,

- "Marshall Plan" study tour programs for managers,

- "Marshall Plan" work tour programs for blue collar workers, and

- Systematic implementation of continuous improvement ("Japanese-style") programs in firms.

When a project has had such relative success where other projects with similar goals have failed, some attempt must be made to understand the different strategies that may account, in part, for the different outcomes. Our task here is not to catalog those successes [see World Bank 2001a, $2001 b$ and Siegelbaum 2001] but to try to give some explanation for them.

\section{Two Strategies for Renewal: Replacement or Transformation}

In the face of decline, there are always two different strategies for renewal: replacement or transformation. Albert Hirschman, in his 1970 classic, Exit, Voice, and Loyalty: Responses to Decline in Firms, Organizations, and States, developed these two strategies as the logic of exit (replacement, the quintessential logic of the market) and the logic of loyalty, commitment, and voice (transformation, the quintessential logic of stable organizations).

When facing decline, a commitment-based strategy "fights" for renewal by fostering the transformation of the given people and structures. An exit-based strategy sees renewal as coming primarily and initially from the outside through "switching," the replacement of the existing people (or at least the top people) and structures by new ones. Transform the old into the new-or throw out the old (to create a tabula rasa) and then import the new; that is the question. All real world situations of decline will call for appropriate combinations of transforming the old into the new (transformation strategy) and replacing the old with the externally-supplied new (replacement strategy).

It should be noted that the replacement strategy depends on finding what is needed from some external source, e.g., from the market. If what is needed is not available on the market then a replacement-oriented strategy will be of little avail. One would have to transform what one already has. For instance, a restructuring strategy for a transitional economy might assume that, as in an advanced market economy, there is a plethora of entrepreneurial and managerial talent, experience, and motivation available "on the market." It is only a matter of getting the macroeconomic conditions and the "investment climate" right, and then the entrepreneurs and managers will "come forth" to take over and restructure the failing firms. Moldova was an example where this replacement strategy was not working. The macro-conditions were stable but foreign investors were not interested given the other opportunities, and there was little or no 
domestic market for entrepreneurial and managerial talent. In the beginning the Moldovans would have to make do with what they had.

But, more generally, there are other reasons to start with a transformation strategy-even if a replacement strategy had more initial feasibility.

The Bank Mission Statement principle of "helping people help themselves" and the Comprehensive Development Framework principle of the "client in the driver's seat" indicate how the two logics might be combined. ${ }^{1}$ If the client is to stay in the driver's seat, then enough of the home-grown old must be transformed into the new so that the client does not "lose his footing" and become so estranged from the change process that his only response is to either cling to the old or to sullenly give in to the new (all the while hoping it will fail). With a sound foundation of footing on the home-grown but transformed old, the client can then take charge of throwing out part of the old and to appropriate and adapt the imported new to make it his own. The alternative is a process externally driven by replacement of the old with the imported new where the clients are "blown off their feet" and are being swept along without any real ownership by imposed conditionalities or other forces outside their control.

Hence the question is: how can the Bank design projects and programs on the basis of enough transformation of the home-grown old into the new so that the clients will thereby gain "ownership" of the process and will have the foundation from which to then open up, acquire, and appropriate the knowledge and experience available to them in a globalized world?

\section{The ARIA Project in Moldova}

The Moldova PSD I/II project, which set up the ARIA Agency for Restructuring and Enterprise Assistance as a quasi-public NGO, made a number of innovations (relative to standard projects) to foster enough home-grown transformation so that the external knowledge and practices could then be imported and applied—with ownership—-to the Moldovan context.

The program of PSD I/II and of the ARIA agency was quite varied. We will go over some of the main features of the program highlighting the features that fostered enough local ownership to then import knowledge and practice and make them locally owned as well. The spirit was to foster a learning process to find the pragmatic ans wers that would work in Moldova, not to supply a blueprint to be implemented.

\section{Achieving self-sustainability: long duration of intervention}

The typical World Bank project cycle of 3-5 years is too short for projects which aim to catalyze such a Gargantuan task as the transformation of centrally planned enterprises and into market organizations with the accompanying change in mentality. In 1994 the World Bank did not have instruments that could span a decade and a three consecutive loans strategy was developed: ${ }^{2}$ PSD I would train hundreds of local consultants that would transform a hundred or so local enterprises, and in the process create demand for management training. PSD II provided for

\footnotetext{
${ }^{1}$ See http://www.worldbank.org/cdf/.

${ }^{2}$ More recently, Adaptable Program Loans and other forms of programmatic lending addresses this problem.
} 
management training and by enabling secondment of best managers abroad initiated a process of substitution of clients and suppliers from the FSU with new ones from the non-FSU countries. Transformed enterprises, managers, consultants now generate demand for a transformation of the business environment-which is what PSD III might have done. In this context, when there are strong local constituencies pushing for reforms, the reforms have a much better chance of being implemented. So the first principle is taking a long term view of the transformation process. Even an orderly exit proved not to be implementable in short term as the most commonly failed conditionalities had to do with the numbers of enterprises that had to be liquidated which the governments refused to do or otherwise avoided doing.

\section{Overview of ARIA Results}

Since 1995, The Moldova NGO - "ARIA" - has completed the restructuring of 90 enterprises. An impact study conducted of the Moldova Project indicates that outcomes have been both positive and significant, in terms of productivity, sales growth, exports, tax payments and other areas. Highlights of the results of the impact study are as follows:

- In 1995, the firms that were to receive project assistance were on average worse off at the outset than comparable Moldovan firms that were never helped by the project.

- By the end of 1999, despite generally worsening economic conditions in Moldova, Project-assisted firms were more productive and paid more taxes per worker, than their unassisted counterparts.

- Project assistance is consistently, positively and significantly correlated with real productivity growth, growth in sales and growth in exports.

- Project-assisted firms have been significantly more successful in attracting foreign direct investment, have changed suppliers more aggressively, and rely less on barter and offsets than other, comparable firms.

- $\quad$ Project-assisted firms have experienced greater management turnover than other firms.

- The Project has, in connection with the restructuring of about 90 enterprises, led to the creation of more than 450 SMEs. About 80 of these SMEs are spin-offs from restructured enterprises and the remainder are either new businesses created from assets sold by restructured enterprises, or independent small businesses which have been attracted to newly-created industrial parks.

- Overall, it is estimated that 9500 employees have been laid off in ARIA restructurings, while a total of 10800 new jobs have been created.

[Source: "New Firms from Old: Building Capital through Enterprise Restructuring." Memorandum by Paul Siegelbaum, Washington: World Bank, May 2001.]

\section{Achieving self-sustainability: large scale of intervention}

To make the home-grown process of transformation self-sustainable, one or two footholds is not enough; the inertia of inherited soviet enterprise behavior and dominant rent-seeking would quickly choke the few firms behaving differently. So the second principle in designing self-help programs is the scaling up to a critical mass of local advisors capable of restructuring mass privatized enterprises, critical mass of managers appropriating more global approaches and management style, and a critical mass of reformed and restructured enterprises with owners that understand the need for a level playing field (that does not favor well-connected, often dying firms of the past). Working with associations of entrepreneurs, publicizing widely achieved results in Moldova and other transitional economies accelerates formation of wider pro-reform constituencies. 


\section{Project "Initiation": Find the "Moving Trains"}

With the agreement reached with the client about the longer duration of project (now possible through Adaptable Program Lending-APLs) and scale of program that allows for more than a few pilot enterprises to be restructured/downsized/created, the critical task of the external task manager (e.g., from the World Bank or other development agencies) becomes identification of the best entry points for the project. The third rule here would be: don't try to start anything new. Instead find where there are domestic beginnings-where local trains are starting to move, no matter how slowly, on their own steam. Then figure out how to use your resources and knowledge to assist—not take over- to assist those home-grown beginnings.

As the poorest of the FSU countries, Moldova did not have the rather mixed blessing of natural resources (oil, gas, or minerals) to allow it to float along on the resource rents without biting the bullet of restructuring. The consensus was there in the early-mid 90s that something had to be done; the questions were who and how?

\section{Finding Leadership}

In view of the politicization and failure of most state-sector "restructuring agencies," the idea was to make ARIA more of an independent quasi-public NGO. That degree of independence made it doubly important to find the right leadership and that, in turn, requires some experience and judgment on the part of the task manager to find that person-a local champion, or better champions. The first one would implement the project while the second one, usually a Cabinet level politician, would play a "godfather" role presiding over the Supervisory Board of the restructuring agency and would provide political support for thorough restructuring measures.

In the case of ARIA, the selected project leader, Georghe Efros, was a Deputy Minister of Industry. Parts of the government at the time would have preferred a less independent and less entrepreneurial individual who would be more inclined to do their bidding. The Bank Project Team insisted on Mr. Efros and it was only after a six month stand-off that the government finally agreed.

The role of the "godfather" cannot be underplayed. In case of Moldova, the Deputy Prime Minister responsible for Economic Reforms was the project champion in the GoM as well as the Chairman of ARIA's Supervisory Council. He was instrumental in the initial years in clearing the way and protecting ARIA from opposition. Especially vocal resistance came from the lobby group of red directors who reacted strongly to proposed restructuring methodology — downsizing enterprises to a level where they (or spun-off parts) could generate positive cash flows. As the government changed and ARIA lost its champion, ARIA came under intensive and continuous scrutiny through various inspections.

Two other countries where similar projects are under implementation or in the final stages of preparation confirm critical importance of the champion. In the first country the original champion is still in power and the project is moving on. In the second, three governments changed during project preparation. In the first two, there were strong champions and the project preparation progressed very well. In the third government there is none and the project is 
stalling. The lesson from here is - given the high uncertainty about the length of office of high officials in the FSU - to look for multiple champions during project preparation. A good example is a new LIL in the Caucasuses where the Supervisory Council of the PIU will have several Government officials, the Rector of the Polytechnics, and representatives of the donors and the private sector.

\section{Building Mutual Trust and Understanding}

For community organizing or consulting for institutional reform to be successful, it is advantageous for the external organizer or consultant to be able to see the client's actual beginning situation (e.g., not treat it as an imagined blank slate) and, indeed, to see that situation through the eyes of the client. ${ }^{3}$ That, in turn, is greatly facilitated by sharing some common cultural and historical knowledge or experience (in addition to the obvious asset of being about to converse in the client's language). This shared knowledge extends from the general understanding of life in a communist country to specific items such as (in this case) Radio Yerevan jokes or the clichés of Partisan movies. Cultural affinity allows an empathetic understanding of the client which allows the client to build trust of the organizer or consultant.

But trust needs to be mutual. The importance of building mutual trust is highlighted by considering the alternative approach of mistrust of the client evidenced by conditionalities. Research [e.g., World Bank 1998] has repeatedly shown the ineffectiveness of conditionalities in getting reforms of any depth implemented. The promise of aid can only buy a false-motivated "intent to reform." If the policies were not adopted by the government independently of the aid, then the policies would tend to be

adopted by aid-hungry governments in spite of continuing doubts of the policy makers themselves, resistance from some quarters within the government, onslaught against the "deal" from the opposition, and general distaste for the whole procedure.

Naturally, doubts and reservations are not voiced at the moment of the aid compact; hence the delusion on the part of the donor that there has been a full meeting of minds. But soon after virtue has been "bought" through aid under these conditions, the reservations and resistances will find some expression-for example, through half-hearted implementation or sabotage of the agreed-to policies - and relations between donor and recipient will promptly deteriorate as a result. [Hirschman 1971, 205]

The genuine desire for reform and change can only be found, not bought, and, once found, trusting the client will cement a better relationship than "just in case" conditionalities.

\section{Horizontal Learning by ARIA}

There are two rather different models for the knowledge-related functions of the Bank, i.e., for the Knowledge Bank. In one model, the Bank has the answers obtained either from economic

\footnotetext{
3 "The change agent must psychologically zip him or herself into the clients' skins, and see their situation through their eyes." [Rogers 1983, 316]
} 
theory and first-world models or from scanning globally to find best practices from developing countries which are then extracted by Bank staff, encapsulated, and retransmitted to clients to be implemented (thus saving the clients the "trouble" of any genuine learning process). That is the storehouse-of-knowledge model. The alternative model is that of being a broker between the clients who have a problem to solve and those who have had some practical success in solving the problem. The Bank as broker then supplies the resources to implement horizontal learning directly between the clients and the people who carried out some best practice example. That is the knowledge broker model.

The learning process of the ARIA model was based on the broker model of horizontal learning. There was no global best practice or 1000-page manual delivered from Washington on how to restructure enterprises in a post-socialist economy. Instead, three companies from (former East) Germany, Romania, and Slovenia were contracted and each was "given" 3-4 enterprises to restructure and provide on-the-job training for young Moldovan consultants. The expectation that consultants from transitional environments would be at least as efficient in an FSU country as the ones from OECD proved to be correct. Best results were achieved with a rather successful model of restructuring utilized in Slovenia. This approach was a perfect example of horizontal learning initiated by the Bank under PSD I. The restructuring model was based on the extensive experience of the Restructuring Fund ("Sklad") of Slovenia and was developed by the founding director of the Sklad, Uros Korze. As Korze had then left the Fund, he was contracted through the Central and East European Privatization Network (CEEPN) to assemble a team and set up a temporary office in Moldova to supply hands-on training to ARIA.

In view of the dubious state of socialist accounting practices for market purposes, the model refocused management on clear cashflow indicators and benchmarks that could be adapted to the real existing post-socialist conditions in Moldova. As ARIA has further developed and adapted the model for their FSU conditions, ARIA has switched from apprentice to teacher to help foster ARIA- like agencies in other countries (e.g., Georgia, Ukraine, and Armenia) through a continuing process of horizontal learning.

\section{Building Local Consulting Capacity}

\section{The "PIU Syndrome"}

There is a common problem with Bank projects that aim to develop local human capital. The Bank sets up a project implementation unit or some other specialized Bank-related organization. The local staff in these organizations are quite keen to make themselves as indispensable as possible to perpetuate their elite status in the Bank-related organization. And Bank HQ staff are grateful to have local counterparts as guides and gatekeepers who speak good English and "know the ropes" concerning Bank procedures. This might be called the "PIU Syndrome." It unfortunately cuts against local capacity-building for the requisite skills outside the PIU since that would tend to make the PIU staff more expendable.

Most Bank projects face some version of the PIU syndrome. In the case of Moldova PSD I/II, the fear was that ARIA would fall prey to the PIU syndrome. The solution was simple and effective. Aside from a small support staff for the director, ARIA would have no permanent staff. All professional staff in ARIA would be there only on short term contracts with a clear understanding that they either had to find a managerial job in the companies they were 
restructuring or find new clients for ARIA-if they are to keep their jobs. This philosophy of making local professionals responsible for implementing changes they were proposing in the client firms was directly opposite of the standard consulting practice (brought by consulting firms from market economies). Imported practice insisted on the advisory role of the consulting services and leaving the responsibility for implementation to very enterprise managers that restructuring programs were trying to teach "new non-soviet" ways of management.

In many cases, the ARIA staff had to "eat their own cooking" by temporarily replacing the failed managers in the client companies. The expectation was that, upon leaving, the staff would then form or join private consulting companies to then be hired directly by the client companies or even to join companies as turnaround managers. Moreover, it was part of the ARIA staff's job to write articles for the business and popular press so this helped both to propagate ARIA's work and to build the reputation of the staff member as a qualified consultant (and future private consultant). Thus instead of hoarding the professional skills in ARIA, ARIA was constantly turning over its staff and seeding the private sector with trained restructuring consultants and turnaround managers.

It should be noted that this staff rollover provision was part of ARIA's public purpose. A private consulting company would have every incentive to retain its trained staff, not to provide incentives for consultants to take over managerial positions in the enterprises they were restructuring or to form their own consulting companies.

\section{The Foreign Advisor Syndrome}

The PIU staff are not the only ones with an incentive to hoard knowledge to perpetuate their status. That is a generic problem with any external consultants who would like a long-term relationship and who thus must be careful not to pass so much knowledge to the client so that the client could get along without them. In the development business, this is a common problem with foreign advisors usually paid by technical assistance funds from their home country-the foreign advisor syndrome.

The foreign advisor problem is exacerbated by the internal incentive systems of grant funded programs and the nature of grant funded contracts in which the recipient country has very little leverage. Thus tenders can have specials conditions about the size of companies, regional distribution, or preventing companies that have already won contracts in the past-effectively limiting potentially best candidates from bidding. Low leverage of recipient country allows contractors to send their weakest consultants, leaving the best for more competitive work in the private sector in the global markets. This combination of low quality foreign advisors and a very complex transitional environment has resulted in very poor results and major skepticism in the region on the value of technical assistance.

This non-market selection process and poor accountability of foreign advisors is one of the main arguments speaking in favor of borrowing for technical assistance by the FSU countries. It enables the client to control the design of the program, to specify the terms of references for the contract and the individual consultants, and to fire the advisors in case of poor performance (very difficult for grant-funded consultants). 
Since ARIA did tap some foreign TA funds, it had to face this problem. The simple and effective solution was two-fold. Firstly, the terms of reference for the foreign advisors were to teach the locals, e.g., ARIA staff, how to solve the problem, not to try to directly solve the problem themselves. Secondly, the TORs were written so that deliverables were precise and allowed for cancellation of the contract in the case of non-delivery. If the foreign advisor wanted to be invited back, it would have to be by the companies formed by the trained staff after leaving ARIA. Thus the incentives for the foreign advisors switched from making themselves indispensable to ARIA - to training the ARIA staff well enough so that the staff could go out into the private sector and get good enough consulting contracts to then invite the foreign advisors back.

ARIA (as well as the Georgian and Ukrainian restructuring agencies) had to learn fast how to extract maximum from the foreign advisors they have hired. The learning curve of local young consultants is very steep and very quickly the foreign advisors find out that providing advise in General Management is not sufficient. The locals soon start demanding specific and more complex techniques such as finance and ISO or continuous improvement techniques (total quality management).

The PIU and foreign advisor syndromes are present in most Bank projects. The strategy of developing and propagating local human capital needs to squarely face these syndromes and find similar solutions to fit the case.

\section{ARIA's Bankruptcy Role}

\section{Special Bankruptcy Agency?}

In "normal market economies," the bankruptcy process (either as restructuring or liquidation bankruptcy) is supervised by courts using trustees to work with the individual bankrupt firms. The first wave of western advice (even in Moldova) was oriented to getting the court system in the post-socialist countries to take on that function in addition to the other revolutionary changes necessary for the transition to a market economy. However, in light of the transitional problems particularly in the FSU, too many firms had to go through either a restructuring or liquidation bankruptcy to be handled by the court-based systems even in the West, not to mention in the transitional economies. Hence there is the need for some transitional agencies that will first "clear the way" by (a) identifying the necessary changes in laws and regulations and (b) demonstrate the benefits of releasing unused or underutilized assets to entrepreneurs. That was one of ARIA's important initial functions.

The idea of a special bankruptcy agency was not new, but there is a growing legacy of failures. In the case of ARIA its role in pilot liquidations (that was called "creation of Industrial Parks") was the most controversial one attracting fierce opposition form the "old guard". It is exactly this role of the liquidator that is - now that the Communists have won absolute majority in the Parliament and control the new Government-being used by the new Government as justification for attempts to shut down ARIA.

What were some of the lessons that both informed the ARIA design as a bankruptcy agency and that were reinforced by the positive ARIA experience? 


\section{No Financing Capacity}

One argument in favor of an advice-giving agency also supplying finance is that the agency should be willing to "put its money where its mouth is." But this argument assumes that it is acceptable for the agency to take over "ownership" of the client-since that is the likely outcome. Finance is not an issue in liquidation bankruptcy. In restructuring bankruptcy, it is important to keep "ownership" and responsibility in the hands of the company management who must turn around the company, not in the hands of the agency. Otherwise, the company will slide into the passive role of urging the agency to supply "just one more round" of financing so that the company will not be an embarrassing "failure" of the restructuring agency. To avoid this trap, the agency should not supply finance-full stop.

While ARIA technically could have tapped into a line of credit, it never did and thus for practical purposes, it did not have a financing capability. ARIA consultants and managers were told to focus exclusively on internally generated funds obtained through sale and leasing of underutilized equipment and space. Furthermore they were told that if they turned to external sources of finance such as EBRD or WB credit lines with interest rates of 22-25\% per annum in dollars the project would be regarded as a failure. Thus the lack of readily available financing was turned from the agency's disadvantage to its advantage in setting the precedent of selling assets (under socialism, enterprises tended to hoard assets even though the assets were unused).

There is another reason why it is a bad idea for a restructuring agency to have a financing capability. When the same agency is supplying both advice and finance, then the two will inevitably become linked by conditionalities. That will then falsify the motive for the client to "take the advice." When restructuring plans are "undertaken" only as a condition to obtain finance, then the company and its management will have little genuine "ownership" of the plans, and the agency will end up financing the costs of not restructuring. ${ }^{4}$

\section{Cram-Down Authority}

In the early and mid-90s, the EBRD launched an ambitious Special Restructuring Program (SRP) in a number of East European countries. The first and perhaps only country where the SRP was fully implemented was Slovenia. Following an international tender, a foreign turnaround specialist was hired to come live in Slovenia and run the program. The SRP was tied to potential finance through the EBRD. In spite of considerable expertise on the part of the restructuring team, only one company was restructured and privatized after several years and the program was quietly discontinued.

What went wrong? One of the key flaws in the program was the lack of any cram-down authority on the part of the SRP. The bankrupt companies had balance sheets full of soft loans from Slovene public sector banks. When the Slovene creditors saw the SRP, which they perceived as being backed by a deep-pocketed EBRD, enter the picture, their soft loans suddenly became "hard legal obligations" of the company. If the company was not refinanced to pay off its "legal obligations" then the creditors could throw the company into liquidation bankruptcy

\footnotetext{
4 "There is a fundamental principle that should run through everything we do: the IFIs should help finance the costs of change-and should not cover the costs of not changing." [Stern 2001, 168]
} 
thus giving the SRP a black eye instead of a much-needed "quick win." Thus the Slovene creditors were not inclined to "take a haircut" on their past soft loans. Since those loaned funds were long since wasted, there was no chance to turn around companies without the creditors taking their share of the losses. Thus time and again, restructurable bankrupt companies had to be abandoned by the SRP due to the lack of any cram-down authority. The wonder is that they were able to do at least one deal.

\section{ARIA Restructuring Bankruptcy Program}

In spite of being sometimes seen as an NGO, ARIA by its founding legislation had a public bankruptcy function. But entry into the program was voluntary on the part of the companies. By joining the program, the company would receive assistance from ARIA to devise a restructuring plan with no finance from ARIA. If the restructuring plan, which would typically involve restructuring debts, was accepted by a sufficient majority of the Creditor Council, then it could be implemented with cram-down authority over any dissenting creditors. But if the company with ARIA's help could not devise an acceptable restructuring plan, then the company would be thrown into liquidation bankruptcy which would probably leave the creditors little recovery on their loans.

\section{Choosing the Entry Point: The "Best of the Worst" Principle}

As there was always some choice of firms, ARIA pursued what has become known as the "best of the worst" strategy. By the "worst" is meant enterprises that have no rents to be squeezed out by interfering bureaucrats and had no local oligarchs trying to take the firm over. Where there are still rents to be had (e.g., natural resource-based firms or tobacco companies), managers and government officials are likely to be more oriented to extracting the remaining rents than undertaking deep restructuring programs. Among the "worst" no-rents-left firms, ARIA wanted to work with the "best" ones- the ones that exhibited some initiative and potential for renewal.

\section{"Best of Worst" Oblasts in Ukraine}

It is important that an ARIA-like project be initiated in a country or region that is small enough so that a critical mass of restructured enterprises, trained managers, and consultants can be reached in a 3-4 year period. Moldova is a small country but in the Ukraine, it was a matter of selecting a few oblasts to work with. Of the 26 oblasts, 22 qualified as being "worst" in the sense that they received more than they contributed to the central government. All oblast governors were interviewed about their readiness to improve the business environment and invited to submit a program about what business climate reforms they would implement if the project was piloted in their oblast. The four that were eventually selected not surprisingly were all from among the 22 receiving budget support from the Center; the self-selection process provided the project again with "the best of the worst".

\section{SME Spin-Offs}

Typically, socialist firms are too big-even in the best of times, not mention in the deep transitional depression in Moldova. Hence restructuring involves not only down-sizing the workforce and selling underutilized assets but also spinning off viable parts of the original firm as independent small and medium-sized enterprises. The spin-offs use what became known as "asset drop-down transactions." The new prospective owners of the spin-off (investors, managers, or workers) would form a new company with some limited initial investment. Then 
the needed assets would be "dropped down" from the "mother firm" into the "daughter firm" using a seller-supplied credit purchase. The daughter firm would make installment payments back to the mother firm over a period of years to pay off the credit. Sometimes the mother firm might take some shares in the daughter in partial payment for the assets. Some shares in the daughter might be collateral that would revert to the mother with any default on the payments so that the daughter might end up more as a subsidiary than as a spin-off.

These asset drop-down spin-offs use seller-supplied credit so these transactions could be and were rather widely used in spite of the rudimentary banking systems in the post-socialist economies.

\section{"Industrial Parks" for New Start-ups}

For the parts of the socialist dinosaurs that could not be saved or spun-off, another creative solution was developed. Many of the middle managers might have "in the back of their heads" ideas for small start-ups. They might not have enough entrepreneurial experience to risk giving up a job to undertake the start-ups. But when their part of the firm is facing complete liquidation, then it might be a viable option. Instead of putting the company space and assets up for public auction, the company might be turned into an "industrial park" where middle managers could exchange some of their unpaid wages for a lease for a certain time period of the space and assets necessary for their new start-up. They would have to scrap together any needed working capital from their own sources. Spaces not taken by these internal tenants would be offered to external tenants. In that matter, a defunct dinosaur with no future prospects might be turned into an industrial park of new start-ups with a real future. Slowly some of the start-ups would grow hiring back a significant portion of the workers from the old company.

\section{Rebirth in an Industrial Park}

\footnotetext{
"One such renaissance occurred through the ARIA-sponsored liquidation of textile maker Spectrul. A new company, Produse Tehnice, was established to manage an industrial part on the Spectrul site in the city of Chisinau. Attracted by the ideal location near major transportation routes, four spin-off textile businesses soon opened up, followed by private SMEs who moved in like Unolucas, a tiny custom design furniture company. Its owners had searched for two years to find an affordable site for expanding their home-based business and were glad to purchase a dilapidated storage facility in the park. After extensive renovations, Unolucas now has expanded manufacturing capabilities, office space, and a showroom. The furniture company is one of 30 companies currently operating in the Spectrul site, where total employment is now 450." [World Bank 2001b, 3]
}

After one or two industrial parks, a unit was formed to be an "industrial park developer" so that each collapsing dinosaur does not have to reinvent the idea. There are two points of particular interest to facilitate the propagation of this experience. Some might argue that the insiders should not be given first option of the inside space for their start-ups; all assets should be put up for public auction. But the point is that it is the possibility of this "neat exit" from the collapsing dinosaur that entices the managers to switch from their usual strategy of lobbying for more subsidies to the more entrepreneurial strategy of going for the start-up. Given their meager resources, the uncertainty surrounding a public auction might lead them to cling to their rentseeking strategy of continuing subsidies. 
Secondly, from the government side, the experience of seeing a few industrial parks with many workers rehired in the emerging SMEs strengthens the government's hand to resist lobbying by other failed firms. Eventually the government sees that this sort of liquidation procedure can be supported without social upheavals and can even offer hope for economic renewal.

In developed market economies, liquidation bankruptcy and new business start-ups are seen as separate economic processes. The down-sized workers will get jobs elsewhere (perhaps with help from a social safety net in the intervening period), and entrepreneurs will come from elsewhere to buy the assets at auction. It's the logic of exit and replacement. There is a wealth of organizational capital so that one need not worry about a low-equilibrium trap that might result from destroying the old without new organization capital coming forth. But in underdeveloped and transitional economies, these market processes are too weak so that, more often than not, failing enterprises will concentrate on lobbying rather than economic renewal. And government officials, fearing the social consequences, will continue to supply the subsidies_-all of which creates a low-level trap.

The industrial park idea addresses this problem. It makes bankruptcy and new business start-ups the two sides of the same coin. The organizational capital of the middle managers and their teams can be directly transformed from the old to the new-without expecting some broader economic processes to replace the old managers with the new entrepreneur-managers from elsewhere.

Spin-offs and industrial parks could be pursued systematically as key restructuring options in any of the transitional economies. In both these cases, as in the other cases, the overarching theme of the ARIA programs is enabling internal transformation, rather than promoting external replacement.

\section{Horizontal Learning for Enterprises}

\section{Trade Before Investment}

The ARIA program was designed from the beginning to put the emphasis on the internal transformation of the Moldovan enterprises rather than trying to attract foreign investors. With sufficient internal restructuring, then the enterprise would be in a position to strike a deal with a foreign partner. From the foreign partner's viewpoint, there should be "dating before marriage" or, in other words, trade before investment.

Moreover, trade with Western companies was of great interest even if it did not eventually lead to some form of investment. Hence a new program PSD II was developed to foster trade connections with Western companies. In spite of all the sophisticated trade promotion programs developed in other countries, one of the crucial needs in Moldova was simply for managers to know enough of a Western language to start communicating first and eventually doing business in the West. ARIA purchased a set of language-training computers from Italy and set up a language training facility for managers. The idea caught on and eventually managers were coming to use the facility both day and night to learn English, Italian, and German. Moreover they were paying for it (in spite of other free courses being offered by the British Council, Goethe Institute, and the like). ARIA was building an avant-garde reputation and managers wanted to be a part of it. 
With the self-confidence born of learning enough Italian or English to get along and with the quality improvements from restructuring, some managers were able to get subcontracting deals with Italian firms (e.g., in shoes, bags, and leather). When other managers saw what their colleagues could accomplish with a little effort, they in turn became interested in the program. The foreign supplier deals that grew in part out of the trade promotion program played an important role in turning around a number of companies in Moldova.

The aim was not to attract foreign investment to "save" Moldovan firms but to help Moldovan firms to transform themselves enough so that they could take advantage of foreign business- to transform enough of the old so that they can appropriate and "own" what could be newly provided from external sources.

\section{"Marshall Plan" Study Tours for Managers}

The "Marshall Plan" has come to mean East-West horizontal learning programs. In the case of Moldova, horizontal learning programs were developed for managers to visit firms in the "relative-West," namely the more advanced post-socialist countries in Central Europe (e.g., Poland, Czech Republic, Hungary, and Slovenia). Since the history of East-West technical assistance is littered with failed or ineffective "Marshall-Plan" programs, what was done differently in the ARIA program?

In some past programs in Russia and other FSU countries, the Soviet-era managers would insist that they could only learn from the advanced Western countries, not from their previous "satellites" in Central Europe. They could only bring themselves to participate in the programs if they could visit the USA or UK or other advanced West European countries. Yet when they discovered how advanced the enterprises were in those countries, then they invariably would say that it was not applicable back in the FSU without purchasing the same latest technology. Thus the trips ended up as little more than enjoyable junkets. From the viewpoint of usable lessons, the world they had seen might as well of been "science fiction."

To avoid these "science fiction" junkets, the ARIA Marshall Plan program was designed to only take managers to see a plausible future for them, e.g., the present realities in Central Europe. Since the trips would require subsidies from the West, some education of Western donors was needed to convince them that trips were needed to the relative-West, not the actual West.

Even when going to the relative-West, managers still need preparatory programs so that they will be able to understand and retain what they are seeing. Hence ARIA ran competitive courses for managers to both prepare them and to weed out those more interested in a junket and those less able to absorb the experience.

Another problem with other Marshall Plan programs is the limited impact of the learning (e.g., only in the manager's firm) and the need to focus the minds of some managers on the lessons. Both problems were addressed by requiring, as a condition to go on the trips, that the returning managers would have to give a certain number of lectures to colleagues from other firms and prepare a number of publications about what they had learned. That both focused the minds of 
the managers on what they could learn and helped propagate the learnings well beyond the managers selected for the trips.

\section{"Marshall Plan" Study Tours for Skilled Blue-Collar Workers}

One of the quite unexpected innovations of the ARIA program was the extension of the study tours to "work tours" for skilled workers. In the relative-West, as well as in the West, there is demand for the gast-arbeiter workers with skills to perform jobs (e.g., at night or over weekends) that domestic workers might not want. Yet the usual gast-arbeiter arrangements create social problems for the host countries.

From the viewpoint of the Moldovan firms and workers, there would be great advantages from temporary gast-arbeiter arrangements to learn new skills and learn about new technologies-not to mention the different pay scales. Returning gast-arbeiters have been a traditional source of skills and investment in eastern countries, such as Yugoslavia and Turkey, that were open to two-way travel.

Could the development potential of gast-arbeiter arrangements be systematically promoted without the accompanying social problems in the host countries? ARIA together with Slovene counterparts worked out a solution —an unexpected consequence of the Slovene consulting relationship. Groups of skilled blue-collar workers would be selected in Moldova according to certain criteria. They would be financed by their companies to be placed for six months working in Slovene companies and living together in apartments. The workers would be paid at minimum Slovene rates which were over five times their usual wages. At the end of the six months, they would have acquired not only industrial and technical skills but also a nest-egg of savings. Some workers would buy a cheap used car in Slovenia and then drive back to Moldova. Others would use their savings for investments back in Moldova.

Another consequence of the program is some subcontracting and investment of Slovene companies back into Moldova. Some workers have come repeatedly. Eventually the Slovene hosts realized that they could subcontract some of the low-end items to be produced back in Moldova by the workers they had trained-perhaps with some special machinery supplied from Slovenia. Thus the "trade" in the form of temporary fixed-term migration leads to trade in goods and eventually to capital investment. Worker placements were so successful for both parties that a company was formed in Slovenia to run the program entirely on a private basis.

Nearby Northern Italy has considerable demand for gast-arbeiters, and there have been the accompanying social problems. The Italian government has financed a study of the SloveniaMoldova experience to see if it could be adapted to Northern Italy. It would seem that this ARIA innovation could be applied broadly in other relative-Western and Western countries. Indeed, ARIA-initiated worker programs in Germany and France, modeled on the pilot program developed in Slovenia, are in operation.

\section{Continuous Improvement Programs}

Interviews with some the repeat workers in the gast-arbeiter program gave some surprising answers to a question about their most valuable experience. One might think that their most valuable learnings would be the new technologies, but the workers often said that the 
technologies they used were, for the most part, familiar to them. What was really new was the experience of working in an industrial culture. After decades of socialism, the workplace spirit and culture in the FSU countries had sunk to a rather low level. One worker said that before when he made a decision, he would not think about how it might cause problems for other workers; he only thought "It won't be my problem." But in the industrial culture of the Slovene factory, he learned to think as part of a team and to take some responsibility for the broader consequences of his decisions and actions.

Some of the experience of an industrial culture could be transferred back to a Moldovan factory if there were enough retur ning workers to form a critical mass. But a more systematic means was needed for this form of restructuring in Moldovan enterprises. Preparation of the PSD I/II programs in Moldova started in June 1994 with a seminar held jointly by the Bank team leader and Prof. Michael Best ${ }^{5}$ of the University of Massachusetts. The seminar presented Iwao Kobayashi's 20 Keys to Workplace Improvement [1990] methodology with the idea that this engineering-based approach would be better understood by ex-soviet managers then more classic management training seminars. However very few of more than a hundred top level managers responded positively to the ideas presented and only one understood the need for, and the principle of, continuous improvement. It is only after few dozen workers from several Moldovan companies passed through six month in-company training programs in Slovenia, Germany, and France did ARIA's initially failing efforts to try to introduce 20 Keys start to produce first results. Kobayashi's book was translated into Russian and training materials were developed for managers and for workers in the client enterprises.

\section{Sweeping Changes in Moldovan Factories}

One of the clearest indices of the deteriorated work culture in many Moldovan enterprises was the massive accumulation of trash. The first of the twenty keys was "cleaning and organizing" the workplace. In the ARIA companies instituting the 20 Keys program, literally truckloads of junk were carried off. The newly cleaned spaces were then painted in a light color that would show any new accumulation of dirt. This act of sweeping, cleaning, and painting by the managers and workers started the long process of rebuilding their self-esteem and pride in their workplace.

The 20 Keys program proved to be a great success in the ARIA and ex-ARIA consultants' restructuring programs to build a quality-oriented industrial culture. Eventually contact was made with Kobayashi's company in Japan and the company in South Africa that holds of the licensing rights for the programs in the West. ARIA obtained the rights to be the exclusive distributor of the program in the Southeast Europe region. Although only half a dozen ARIA restructured companies initially agreed to pursue continuous improvement according to 20 Keys, the early results were so impressive that now over a score of Moldovan companies have adopted the program. The idea was re-exported to Slovenia and the Slovene government developed a state-supported program that subsidizes introduction of the 20 Keys methodology to 60 Slovene companies (selected through tender). The international organization of 20 Keys practitioners was so impressed by the applications of the program in Moldova that their next world congress will be hosted by ARIA in Moldova.

\footnotetext{
${ }^{5}$ See Best 1990.
} 


\section{A Hirschmanian Approach to Social Learning and Change}

Some insight into the Moldovan ARIA experience can be gained by reflecting on Albert Hirschman's vision of economic change. The Hirschmanian approach of "unbalanced growth" was originally described as the contrast with the idea of a large coordinated "big push" program of change (e.g., as specified by a 'Christmas tree' of conditionalities) implemented by the central government in an underdeveloped country. The essential point was that if a country had the institutional capacity to implement a comprehensive "balanced growth" program of change then it would hardly be an underdeveloped country. Assuming that institutional capacity in project design was just assuming that which needed to be developed in the first place. Hirschman tried to outline in more practical terms how institutional change might take place.

Instead of top-down across-the-board change, one needed to find where change was afoot in the small.

I began to look for elements and processes...that did work, perhaps in roundabout and unappreciated fashion. [T] his search for possible hidden rationalities was to give an underlying unity to my work. ... [T] he hidden rationalities I was after were precisely and principally processes of growth and change already under way in the societies I studied, processes that were often unnoticed by the actors immediately involved, as well as by foreign experts and advisors." [Hirschman 1984, 91-3]

The Best-of-the-Worst principle is a strategy for finding those entry points. Learning and change is driven by problem-solving. Not all problems can be attacked at once so attention and aid is first focused in the small on the sectors or localities where some of the preconditions are in place and where initiative is afoot on its own-where the old is starting to transform itself into the new. The preconditions for learning and change are more likely to be in place among those facing the most salient problems, namely among "the Worst" where change can no longer be avoided by extracting further rents. Amongst "the Worst" there are those who are willing to take the initiative in a pragmatic learning process; they are the Best of the Worst.

Edmund Burke long ago captured the idea that difficulties (problems) give rise to learning, and that one learning leads on to more problem-solving.

[Difficulty] has been the glory of the great masters in all the arts to confront, and to overcome; and when they had overcome the first difficulty, to turn it into an instrument for new conquests over new difficulties;... . He that wrestles with us strengthens our nerves, and sharpens our skill. Our antagonist is our helper. This amicable conflict with difficulty obliges us to an intimate acquaintance with our object, and compels us to consider it in all its relations. It will not suffer us to be superficial. [1937 (1790), 299-300]

Those who have more rents to collect still "suffer ...to be superficial"; the others have to face their problems. 
Hirschman then envisaged that the initial small successes would create pressures through the forward and backward linkages to foster learning and change that is nearby in sectorial or locational terms (in contrast to changes dictated by conditionalities). One thing leads to, induces, elicits, or entrains another thing through chains of "tensions, disproportions, and disequilibria." Hirschman at one point refers to the principle of unbalanced growth as "the idea of maximizing induced decisionmaking" [1994, 278]. The problem-solving pressures induced by unbalanced growth will call forth otherwise unused resources and enlist otherwise untapped energies. As a project moves from one bottleneck and crisis to another (in comparison with the smooth planned allocation of resources in a project), then "resources and abilities that are hidden, scattered, or badly utilized" [1961, 5] will be mobilized.

Sometimes these projects might be initially in areas more isolated from the forces reinforcing the low level traps (e.g., corrupt or predatory local governments). The successes could then be broadcast through publicity, public courses, and horizontal learning programs to those facing similar problems. That will start to break down the paralyzing beliefs that "nothing can be done" and will thus fuel broader initiatives that take the early wins as their inspiration and benchmark. The successes will be copied and emulated to slowly build a constituency for change to a scale where it can have a reinforcing political effect.

\section{Putting the Pieces of the Puzzle Together}

Hirschman uses the metaphor of a jigsaw puzzle for the set of problems facing a developing country [1961, 81-2]. One could imagine a rather superhuman act of putting all the pieces together at once to solve the puzzle. Indeed don't those who have seen and studied seemingly similar puzzles put together elsewhere have that knowledge? That is the comforting fantasy of those who promote comprehensive, integrated, and balanced reform programs. Do all these things together (so that it looks like the "picture on the puzzle box") and you will have solved your problems! But for the variety of reasons outlined above, countries cannot just solve all their problems at once. They must start with a few pieces that fit together and try to work outward to find other pieces that fit. Not all entry points are equal. Certain pieces of the puzzle may have nearby connections and linkages that allow building that part of the puzzle quickly-as opposed to parts whose solution might give little insight or impetus to solving the nearby parts. Perhaps someone who has seen similar puzzles solved would be a good coach to suggest promising entry points or fruitful directions for progress. No doubt it would be helpful to study the "picture on the box." But the actual solving of the puzzle is a piecemeal process starting in one or more propitious places and working outward through fruitful linkages to finally arrive at the new overall configuration.

\section{Conclusions}

The ARIA Project illustrates some of the policies open to the Bank when macro-stability is not enough, when outside entrepreneurs and managers are not coming to replace the local ones to turn around the firms.

The success of the ARIA project in Moldova could also be understood in the context of a Hirschmanian approach to social learning and change: finding the right decentralized entry points in the small among the best of the worst, developing the project as a pragmatic learning process, spreading the early wins through horizontal learning programs and natural linkages, and building a constituency for change on a scale large enough to then support broader political and institutional change over a longer term. 
The project also supplies a perspective on the current debate about globalization. Often that debate is posed in terms of whether or not a country should be "open" to globalization. The ARIA experience indicates that this is not the right question. Of course, a country needs to be open to whatever is compatible with and will augment its autonomous development. Gandhi used a good metaphor for the openness that is compatible with one's autonomy. "I do not want my house to be walled in on all sides and my windows to be stuffed. I want the cultures of all lands to be blown about my house as freely as possible. But I refuse to be blown off my feet" [Quoted in Datta 1961, 120] By building on enough transformation of their old into a new foundation, the local change-agents could remain "on their feet" and have the self-confidence to seek out, assimilate, adapt, and own the external knowledge, experience, and relationships available to them in a globalized world.

\section{References}

Best, Michael. 1990. The New Competition: Institutions of Industrial Restructuring. Cambridge UK: Polity Press.

Burke, Edmund 1937 (1790). Reflections on the French Revolution. The Harvard Classics: Edmund Burke. C. Eliot. New York: Collier: 143-378.

Datta, Dhirendra Mohan 1961. The Philosophy of Mahatma Gandhi. Madison: University of Wisconsin Press.

Hirschman, Albert O. 1961 (1958). The Strategy of Economic Development. New Haven: Yale University Press.

Hirschman, Albert O. 1971. A Bias for Hope: Essays on Development and Latin America. New Haven: Yale University Press.

Hirschman, Albert O. 1984. A Dissenter's Confession: "The Strategy of Economic Development" Revisited. Pioneers in Development. G. Meier and D. Seers Eds.. New York: Oxford University Press: 87-111.

Hirschman, Albert O. 1994. A Propensity to Self-Subversion. Rethinking the Development Experience: Essays Provoked by the Work of Albert O. Hirschman. L. Rodwin and D. Schön. Washington: Brookings Institution: 277-83.

Kobayashi, Iwao 1990. 20 Keys to Workplace Improvement. Portland OR: Productivity Press.

Rogers, Everett 1983. Diffusion of Innovations. $3^{\text {rd }}$ edition. New York: Free Press.

Siegelbaum, Paul 2001. New Firms from Old: Building Capital through Enterprise Restructuring. Memorandum May 2001. Washington: World Bank.

Stern, Nicholas. 2001. A Strategy for Development. Washington: World Bank.

World Bank 1998. Assessing Aid: What Works, What Doesn't, and Why. Washington.

World Bank 2001a. Redeploying Moldovan Assets: Creating New Enterprises from Old. Report of Private and Financial Sectors Development Sector Unit. Washington: World Bank.

World Bank 2001b. SME Spin-offs: Industrial Restructuring in Moldova. SME Facts: News about World Bank SME Initiatives. 2 (6 April), 1-4. 